\title{
Access to scientific research papers
}

Dear Sir,

Congratulations on the successful publication of the $40^{\text {th }}$ volume of our journal. As mentioned in your editorial it is indeed a landmark. The quality of the academic content of the journal has gone up by leaps and bounds over the last few years. We have also come to expect the journal regularly and on time. As members of APSI we are proud to be associated with IJPS which is now on par with most international journals. Hats off to you and your team for the same!

Your point about IPR (intellectual property rights) and opposing views vis-à-vis the publisher and the author are very valid. The concept of "open access journals" could probably attempt to remedy this gap. Open access journals are journals that use a funding model that does not charge readers or institutions for access. For a journal to be included in the directory of "open access journals" it is mandatory for users to have the right to "read, download, copy, distribute, print, search or link to the full texts of these articles". Quality Control is in the form of peer-review or editorial quality control. Free flow of information using "open access journals" is now gaining momentum. ${ }^{[1,2]}$ The following are good links to information about open access and open access journals -

Directory of open access journals (Lund University) http:// www.doaj.org/

FreeMedicalJournals.com http://www.freemedicaljournals. $\mathrm{com} /$

Budapest Open Access Initiative http://www.soros.org/ openaccess/index.shtml

Open Access News http://www.earlham.edu/ peters/fos/

In this day and age of emails and with most journals accepting online articles one avenue is yet open to us i.e. obtaining the article from the author directly via an email request (akin to reprints). So for someone who is genuinely interested in obtaining the article and willing to go the extra mile for it, the absence of "free full access" journals need not pose an insurmountable barrier. Personal communication with the author usually does produce the article more often than not. 
Vinita Puri, Sanjay Mahendru

Department of Plastic, Reconstructive Surgery and Burns, Seth GS Medical College and KEM Hospital, Parel, Mumbai - 400 012, India

Address for correspondence: Dr. Vinita Puri, Department of Plastic, Reconstructive Surgery and Burns, Seth GS Medical College and KEM Hospital, Parel, Mumbai - 400012. India. E-mail: vp@kem.edu

\section{REFERENCES}

1. Warlick SE, Vaughan KT. Factors influencing publication choice: Why faculties choose open access? Biomed Digit Libr 2007;4:1.

2. Suber P. Open access, impact and demand. BMJ 2005;330: 1097-8. 